\title{
METHODOLOGY
}

\section{Features of Contemporary E-learning Development in the Digitalization Era}

\author{
A. Goloborodko ${ }^{1}$, T. Nosova ${ }^{2}$ \\ University of Telecommunications, Kyiv, Ukraine ${ }^{1,}$ University of Customs and Finance, Dnipro, Ukraine ${ }^{2}$ \\ Corresponding author. E-mail: alona.goloborodko.decor@gmail.com \\ Paper received 23.06.20; Accepted for publication 17.06.20.
}

https://doi.org/10.31174/SEND-HS2020-237VIII41-07

Abstract. The article conducts research on the e-learning features, trends and directions that is stimulated by the modern globalization processes and digital economy intensification. The difference between distance and e-learning is given, as well as the most popular online learning platforms are systematized.

Keywords: E-learning, distance learning, digitalization, online learning platforms.

Introduction. In 1990, no one thought about how the advent of the Internet would affect the economy. Many people did not even have an idea of what the World Wide Web was. But nowadays the number one topic for the entire business environment is the issue of cloud technology or e-commerce. Knowledge of the e-commerce technologies features and advantages provides enterprises with the commercial goals achievement.

Analysis of recent research. Many scientists have dealt with the theoretical basis of the e-learning development within the digitalization context. Among them, there are T. Pushkareva [1], O. Melnyk [1], N. Yusha [2], L. Lapidus [3] and others. They revealed the main approaches to e-learning understanding and many other important scientific issues. However, the scientists' works do not cover the issues of contemporary e-learning development in the digitalization era.

The aim of the article is to study and highlight the contemporary e-learning development features, trends and directions within the digitalization era.

Research methods. The article uses such general scientific research methods as scientific cognition and dialectic method, general scientific cognition methods, methods of logical generalization, system analysis, and synthesis.

The results of the study. The information technology evolution and the further digital economy formation are contributing to the online education global market growth This segment is becoming increasingly attractive to investors. For instance, Google has invested 45 million dollars in foreign languages learning service and crowdsourcing translations named Duolingo. Investors have invested 6.7 million dollars in Busuu, which is a social network that connects speakers who want to learn a foreign language for free with tutors.

E-learning is one of the information society and digital economy development tools. It contributes to the forms renewal, tools, technologies and teaching methods; expanding access to knowledge for all mankind, taking into account the possibility of building their own learning trace, modern students' skills formation required by society.

Very often e-learning is considered as synonymous with the concept of "distance learning". But this is not quite true. These terms are interrelated, but each carries its own meaning. There is distance learning that is not e- learning, for instance when learning materials are delivered by courier or mail. Just the same is for e-learning that sometimes cannot be considered as distance learning.

Distance learning means the gaining knowledge process, when the student and the teacher are at a distance, and the material transferring method does not matter at all. In e-learning, educational material is generally presented only in electronic form. E-learning is a way of organizing the educational process based on the use of ICT, multimedia or Internet technologies in order to create a massive education system and retraining, improving the education quality by improving access to resources and services, as well as remote knowledge exchange and teamwork [1].

The dynamics of the Ukrainian online education market development in the B2C segment is positive. It provides many additional opportunities, especially for busy people, as it allows people to study the material at a convenient time and has a deadlines-free structure. E-learning is quite comfortable for antisocial and closed people.

However, despite all the advantages of e learning, in our opinion, such education system cannot be reduced as a separate educational form. Offline learning system provides better education and therefore forms more competitive intellectual capital. In addition, technical equipment of population in some regions of our country is still at a low level.

All this help us to highlight the main benefits of Ukrainian offline education:

First, there are advantages of audience socialization and direct communication during the education.

Second, direct information exchange system without barriers that mean direct communication: teacher-listenerteacher.

Third, instant correction of work performed errors and shortcomings, obtaining answers to questions.

Fourth, the acquisition of teamwork skills, gaining leadership qualities, the effect of competition between students.

Fifth, the access to the material and technical educational institution infrastructure, software products, library funds, visual samples, etc.

The most popular Ukrainian e-learning services are foreign language acquisition. The average conversion rate is $2 \%$. Conversion at the level of $2 \%$ means that only $2 \%$ of all users who learn a foreign language via particular 
service buy subscriptions, others $98 \%$ prefer to receive educational services free. How does it rate a $2 \%$ conversion? The answer can be given on the basis that Freemium / Free-to-Play business models usually has a conversion of 0.5 to $1.5 \%$. It would seem that $2 \%$ is a lot, but for the online education market, this level can be considered as low. Thus, the Ukrainian online education market belongs to the fast-growing segment, but even with sufficient investment, low conversion will not be able to bring high profits to business. That is why is quite difficult to achieve high commercial results and effectively manage e-commerce in this segment.

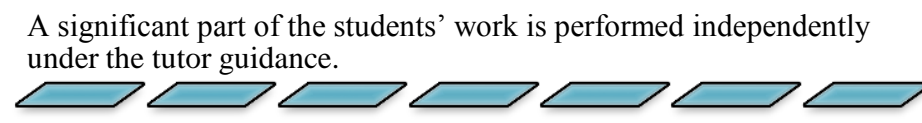

Saving the time (according to Cedar Group, e-learning takes approximately $35-45 \%$ less time).

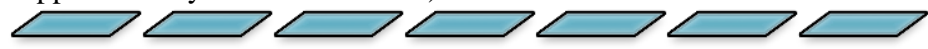

Increasing the memorization speed of educational material by $15-25 \%$ in compare to full-time learning forms.

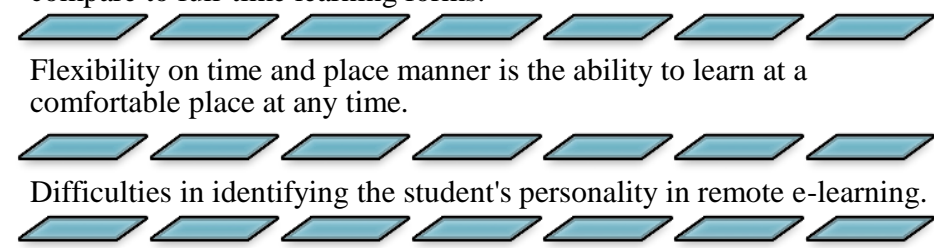

Lack of certified control systems, only the strong self-management or self-motivation skills are lead to acquire knowledge.

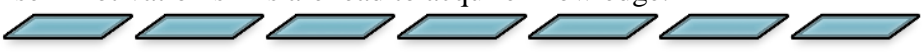

Access to education for all students categories and lower tuition fees.

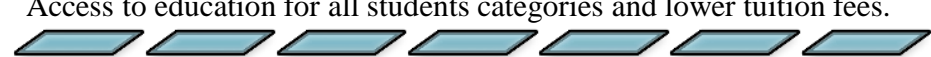

Ability to return to material that is not entirely clear, an unlimited number of times.

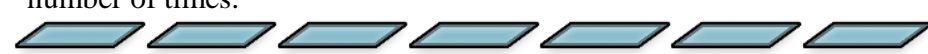

Limited personal access to the teachers and difficulties with getting answers to questions.

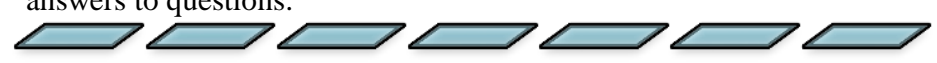

Fig. 1. Basic e-learning characteristics

Successful projects have appeared on the electronic English language learning market in Ukraine for last years [4]:

$\checkmark \quad$ BBC Learning English. This service is a part of BBC World Services. It provides resources and activities for different levels of study.

$\checkmark \quad$ British Council Learn English is high-quality resource that is created by the British Council, the world's English teaching experts, UK government department for sharing a common Britain history, heritage and language. There is an opportunity to improve grammar, vocabulary, speaking or audio language skills on their site.

$\checkmark \quad$ Duolingo is a platform for learning foreign languages. You could learn English whether on website or use a mobile App. Duolingo is appropriate for freshmen. At the same time introductions to the Intermediate and Advanced courses are also available.

$\checkmark \quad$ Lingualeo is an educational site entirely dedicated to learning English. The site has free or subscribed training courses.

$\checkmark \quad$ engVId is site with video lessons for learning English, divided by thematic of study. Those who intend to prove their language proficiency by using one of the two most common and recognized worldwide English language tests, IELTS or TOEFL, can take advantage of special video lectures to prepare.

$\checkmark \quad$ Memrise is an original learning foreign languages platform that uses a card system. The users them- selves can also create content. In 2017, the app won the Best Play of the Year category from the Google Play Awards.

$\checkmark \quad$ TED is an organization dedicated to motivational lectures in English. It is great for viewers with existing English knowledge who want to improve their audio skills. Subtitles are also available on the site.

$\checkmark \quad$ Loyal books is a library of free e-books and audiobooks by different languages. It is an effective way to improve your vocabulary.

$\checkmark \quad$ Lingva.Skills (www.lingva.ua) is Ukrainian social platform within the mass foreign language study campaign "Ukraine will speak English!" for all citizens of the country.

$\checkmark \quad$ Massive open online courses (MOOS) allows people to study with teachers from the world's leading universities, i.e. people who are important in the academic world, join a multinational student group (in discussion forums), get a certificate confirming successful passing the entire course.

The largest online platforms teach videos and evaluate the acquired knowledge [5, 7].

The most popular online learning platforms are:

1) Coursera (www.coursera.org) is the leader of online platforms according to the ranking of Time magazine website, which was founded in 2012. This is due to the following: the list of partner organizations is constantly expanding, the number of courses is more than 1600 , and 
they are prepared by 140 universities from 28 countries in various disciplines (biology, mathematics, economics and finance, engineering, medicine, law, art, totally 25 categories). Coursera cooperates not only with educational institutions in the United States (Stanford, Princeton, California, Columbia), universities of individual states (Tennessee, New York, Nebraska), but also leading cultural organizations (e.g., the Museum of Natural History). Tuition is provided both on a paid basis and free of charge for some courses. One can choose the language of instruction. The structure of training consists of lectures, seminars and current assessment. Upon completion of the courses, successful students are issued an identified certificate (Signature Track).

2) Khan Academy is an 'open' online platform for helping schoolchildren, founded by the American Salman Khan (www.khanacademy.org). The Khan Academy website presents short (5-15 minutes) video lessons from various disciplines, assessment of the knowledge level is also offered. Lessons are taught in English, but they are supplemented by subtitles in many languages. There is a Russified version of the "Academy", which is constantly updated with translated materials.

3) EdX (www.edx.org) is a joint project of Harvard University and MIT, which offers online training in 24 areas: computer technology, chemistry, mathematics, ethics, music, statistics, and literature. Tuition is provided both on a paid basis and free of charge for some courses. Online courses repeat real lectures given at Harvard, Cornwall University, the Lausanne Federal Polytechnic School, the Universities of Hong Kong, Kyoto, and Beijing, so those who study must have the appropriate basic knowledge. Some courses are enrolled in academic hours and may be taken into account when considering a scholarship application at partner universities.

4) Courses at edX are provided with the necessary didactic materials, divided into modules, covering lectures, practical material, homework, methods of control and assessment (tests, exams). Successful students receive a certificate upon course completion.

5) Udacity - (www.udacity.com) is a private platform, focused on the IT-topics study (computer science, programming) and others (mathematics, business, design, physics, biology, etc.). It was created by a team of scientists led by Sebastian Trun, a Google engineer who specializes in robotics.

Currently, the platform cooperates with Google, the financial giant Bank of America, the social network Facebook and other companies. In total, Udacity offers more than three dozen courses at three levels of difficulty: beginner, experienced, professional. Materials are presented as a lecture material or assessment tools. The main language is English, but some courses have subtitles in other languages. A certificate evidences the successful completion of the courses, some employers take into account such a diploma.

6) Canvas Network - (www.canvas.net) is a project that has a wide variety of courses, which conduct different training levels and personal activities: scientists, artists, practitioners. Courses do not have a single approach to teaching. They include video lectures, packages of practical classes. A certificate at the end of the course may or may not be issued. Canvas Network offers free and paid courses. Conditionally free provide for the purchase of additional educational materials (manuals, literature), paid ones allow you to get credits in the system of continuing education.

7) Udemy (www.udemy.com) is the site of the platform "Udemy" has educational projects divided into 16 categories, including computer science, humanities, as well as hobbies and needlework, art and photography. Instructors with practical experience teach Udemy courses. Jack Welch, CEO of General Electric, and a top manager with vast managerial experience, designs one of the most popular courses. All materials on the site are paid; the payment cost can vary from 10 to 500 dollars. You can get a discount by using a coupon. Upon completion of the course, students receive a certificate, including confirmation from big companies - Cisco Systems, Microsoft Corporation, Financial Industry Regulatory Authority and others. Companies and professionals can create and sell their own courses on the Udemy platform (the average salary of a lecturer can be about $\$ 7,000$ per year).

8) Prometheus (www. Https://prometheus.org.ua) is Ukrainian free online education platform created in 2014. Among its partners, there are the best higher educational institutions of the country: National University of KyivMohyla Academy, Kyiv National University named by Taras Shevchenko, Kyiv Polytechnic Institute, Ukrainian Catholic University and Lviv IT School (LITS). Courses at Prometheus are available online at any time; there is a mobile application for Android and iOS. Prometheus courses are built on a system of interrelated cycles, for example, there is a cycle of courses for ZNO preparation (Ukrainian external assessment at government level).

The use of electronic signatures keys is an important tip for providing high level of reliability and information security by a modern software and hardware complex. The development of such technology is extremely important for distance and e-learning development.

Electronic digital signatures (EDS) services include registration of applicants; providing reliable means of EDS; assistance in generating public and private keys; maintenance of enhanced key certificates of applicants, including certification of users public keys, distribution and storage of enhanced key certificates, management of the enhanced key certificates status and information dissemination about the key certificates status; provision of time recording service; consulting services by the client request.

The main condition for effective usage of abovementioned technologies is the availability of the Internet [6].

The fact that world leaders in e-learning such as USA, Finland, Singapore, South Korea, Canada, Australia, New Zealand are also leaders in the World economy is needed to be mentioned. This necessitates the e-learning development as an additional, aimed at gaining deep knowledge and future professional development tool or retraining tool. That is why e-learning, or system which uses an ICT, should be rationally integrated into modern education, standing along with the latest and traditional learning tools.

Conclusions. E-learning is one of the development tools in the digital economy era. It contributes to the renewal of forms, tools, technologies and teaching methods; 
expanding access to knowledge for all humanity, taking into account the possibility of building their own learning trace; formation of contemporary students' skills that modern society needs more in the context of digitalization. However, this form of learning cannot completely replace offline learning, because of limited socialization, lower learning efficiency, lack of individual approaches within the learning process and much more. Therefore, it is advisable to integrate rationally the e-learning system into the traditional offline educational system.

\section{REFERENCES}

1. Pushkareva T., Melnik O. E-education and its development in
Ukraine. Computer in school and family №3, 2013. P. 16-17.

2. N. Yusha. The specifics of the formation and dissemination of e-education in educational institutions. E-journal "Effective Economy".

$U R L:$ http://www.economy.nayka.com.ua/?op $=1 \& \mathrm{z}=7270$.

3. Lapidus L.V. Digital economy: management of electronic business and electronic commerce, textbook / L.V. Lapidus. Moscow: INFRA-M, 2020, - 479 P.

4. Top 11 online resources where you can learn English for free URL://www//http://tvoemisto.tv/exclusive/top11_onlaynresursiv _de_mozhna_vyvchyty_bezkoshtovno_angliysku_94704.html 